\title{
Depression and Cerebrovascular Disease: Could Vortioxetine Represent a Valid Treatment Option?
}

\author{
Mauro Giovanni Carta ${ }^{1, *}$, Andrea Norcini Pala ${ }^{2}$, Gabriele Finco ${ }^{3}$, Mario Musu $^{3}$ and \\ Maria Francesca Moro ${ }^{1}$ \\ ${ }^{I}$ Department of Public Health and Clinical and Molecular Medicine, University of Cagliari, Cagliari, Italy; ${ }^{2}$ New York \\ State Psychiatric Institute (NYSPI), New York, NY, USA; ${ }^{3}$ Department of Medical Science, University of Caglairi, Italy
}

\begin{abstract}
Introduction: Depression and cerebrovascular atherosclerosis often occur in comorbidity showing neuropsychological impairment and poor response to antidepressant treatment. Objective is to evaluate if new antidepressant vortioxetine may be a potential treatment option. Mechanism of Action: Vortioxetine has 5-HT3, 5-HT7 and 5-HT1D antagonists, 5-HT1B partial agonist and a 5-HT1A agonist and serotonin transporter inhibitor property. Efficacy and safety in Major Depressive Disorders and in cognitive impairment: The majority of trials (one of them in older people) showed efficacy for vortioxetine against placebo and no differences against other active treatments. The Adverse Effects ranged from $15.8 \%$ more to $10.8 \%$ less than placebo. In the elderly, only nausea was found higher than placebo. Effects on arterial blood pressure and cardiac parameters including the ECG-QT segment were similar to placebo. Elderly depressive patients on vortioxetine showed improvement versus placebo and other active comparators in Auditory Verbal Learning Test and Digit Symbol Substitution Test scores. The inclusion criteria admitted cases with middle cerebrovascular disease. Conclusion: The mechanism of action, the efficacy on depression and safety profile and early data on cognitive impairment make Vortioxetine a strong candidate for use in depression associated with cerebrovascular disease. This information must be supported by future randomized controlled trials.
\end{abstract}

Keywords: Cerebrovascular disease, major depressive disorders, vascular depression, vortioxetine.

\section{INTRODUCTION}

Cerebrovascular atherosclerosis is a leading public health concern; atherosclerotic disease has represented up to now the leading cause of death and morbidity in developed countries and today the determinants of atherosclerosis are increasing in new developing countries. Thus, in the future they are expected to be the major causes of morbidity and mortality around the world [1] Cerebrovascular atherosclerosis determines severe acute events and it is associated with early cognitive impairment [2] Stroke is the third cause of mortality and the leading cause of long-term disability in western countries, with 800,000 events per year in the United States alone and it is rapidly increasing around the world $[1,3]$ We can consider that for every identified episode, about five silent, unrecognized strokes can be calculated [4].

Older age, male, family history of vascular disease, problems of blood pressure, cholesterol/high-density ratio, metabolic diseases (specifically diabetes mellitus), and tobacco addiction have been clearly identified as determinants of neuro-atherosclerosis [5]. As the risk factors are well identified, it is possible to plan and carry out proper prevention programs, but one of the factors that lower patients' compliance with therapy or prevention programs is the frequent cooccurrence of depressive episodes [6].

*Address correspondence to this author at the Department of Public Health and Clinical and Molecular Medicine, University of Cagliari, SS 554, Bivio Sestu, 09142 Monserrato (CA), Italy; Tel: +39 070 499994;

Fax:+39 070 6093498; E-mail: mgcarta@tiscali.it
Patients suffering from chronic disease have a risk of depressive disorders two or even three times higher than the general population $[7,8]$. The prevalence of depression has been found between $15-25 \%$ of patients with cardiometabolic diseases, diabetes and stroke [9, 10] (Ali et al. 2006; Hadidi et al. 2009). A recent survey conducted by our group with a case-control methodology and the use of clinical diagnosis has found that nearly one out of four people suffering from carotid stenosis had suffered from Major Depressive Disorders during their lifetimes with a risk almost 6 times that of the control group. However, no increased risk of bipolar disorder was found in the lifetime of our cases compared to controls, although a tendency toward a higher frequency of positivity in screening for Bipolar Spectrum was shown [11].

Patients with neurovascular disease and with concomitant depression have had poorer clinical outcomes and higher mortality, as well as more risk of functional disabilities [12] The treatment of depression improves the course of coronary heart disease and improves patient compliance with various cardiac interventions as well as the prevention of acute events [6].

\section{DEPRESSION AND CEREBROVASCULAR DISEASE}

Depression and atherosclerosis are common conditions that often occur in comorbidity. Evidence shows that comorbidity may emerge because people with depression have a high risk of atherosclerosis and, vice versa, people with atherosclerosis, especially with neuro-vascular disease, are at risk of depression. These close links have led to postulating 
that the so-called vascular depression hypothesis identifying a specific subtype of depression in late life [13] appear to be characterized by the following specificities [14].

1) patients with Vascular Depression have more hyperintensities at brain Magnetic Resonance Imaging (MRI);

2) patients with Vascular Depression and MRI hyperintesities show greater neuropsychological impairment than patients with depression with early onset;

3) cases with severe MRI hyperintensities show poor response to antidepressant treatment, especially when brain damage is associated with deficits in executive functioning;

Even though the condition has produced a large debate in literature there is no agreement about the diagnostic criteria of vascular depression [14]. The Alexopoulos's group emphasized the relevance of the onset of depression after age 65 accompanied by executive dysfunction impairment [15] in contrast, others have proposed as key features depression with subcortical ischemia and MRI evidence of cerebrovascular pathology $[16,17]$.

As this inhomogeneity has made it difficult to compare research, an attempt was made to identify the single most accurate element in defining the spectrum of disorders [18] and this showed deep white matter lesions as the better indicator. In any case, both executive function and brain alterations are closely related: in fact, Kim et al. [19] found a previous cerebrovascular attack as a specific determinant associated with depression and executive impairment and not with depression without a deficit of cognitive functions. Accordingly, other surveys found that subcortical hyperintensities on magnetic resonance imaging were associated with poor response to antidepressant treatment [15] but other studies have found a similar poor outcome with antidepressants in people with depression and a deficit of functional impairment [18].

The cognitive impairment of vascular depression affects verbal memory, executive functioning, visuospatial functioning, information processing, perception and attention [20].

Studies on neuroimaging have documented the localization of hyperintensities in the subcortex and the frontal area $[21,22]$ with concomitant pyramidal neuronal abnormalities and reduction of density [23]. A more recent study has extended the morphometric abnormalities in late-life depression to the caudate nucleus, finding a significant reduction in neuronal density both in the dorsolateral and ventromedial areas of the caudate nucleus with no changes in glial density or neuronal volume [24].

Recently, it has been suggested that the factor that may determine the genesis of both depression and cerebral vascular damage is to be found in the oxidative stress secondary to hypo-perfusion [25] In this framework Li and coll [26] have advanced two not excluding hypotheses: 1) the inflammatory one, which deals with the increased production of proinflammatory cytokines resulting from brain ischemia in cerebral areas and 2) the glutamate hypothesis, considering that stress-induced glucocorticoids via activation of the hypothalamus-pituitary-adrenal axis lead to dysfunction and can impair glutamatergic transmission. Both ways, with different mechanisms, may influence activity in the central nervous system of neurotrophins as a brain-derived neurotrophic factor (BDNF) and vascular endothelial growth factor (VEGF). These neutrophins attenuate apoptosis in cultured neurons, stimulate neurogenesis, increase survival and protect neuronal tissues from cell death induced by ischemia or depression [26]. Although these studies open up future prospects for therapeutics, the treatment of vascular dementia is still under debate and still represents a relevant issue.

\section{ISSUES IN THE TREATMENT OF VASCULAR DE- PRESSION}

Selective serotonin reuptake inhibitors (SSRIs) are recommended as first-line antidepressant treatments for vascular dementia but only few randomized clinical trials (RCTs) with relatively small sample sizes have been carried out on the use in dementia of SSRIs [27]. On the other hand, in depression comorbid with cardiac atherosclerosis no evidence of active harm (SSRI vs placebo) was detected in two metaanalyses even when patient samples were carefully selected (for example, patients with comorbid conditions were excluded, thus making the samples far from real practice) $[28$, 29].

SSRIs can improve cognition in patients with stroke, this may be due to the increase in the expression of the brainderived neurotrophic factor (BDNF) in the hippocampus [30]. However, the SSRIs may cause a higher incidence of side effects [30] not only in vascular cerebropathies, but also in other forms of atherosclerotic diseases associated with depression [31]. In fact, the use of SSRIs in depression with vascular neuropathy and other forms of atherosclerosis has been found to be associated with bleeding $[32,33]$ the risk of arrhythmia [34] and associated with longer-term risk of an adverse prognosis [35].

In addition to poor response to antidepressants, it can be considered that cardiovascular chronic diseases could be contraindicated for the use of ECT therapy [36]. The problem-solving therapy has been proposed as an alternative to antidepressant medication, but there are very few data available of studies with small patient samples [37,38]. The employing of evidence-based psychotherapy such as Cognitive Behavior Therapy or Interpersonal Therapy, with modifications to accommodate cognitive impairments, is indicated as an add-on to antidepressants but there is a lack of randomized clinical trials showing efficacy in this specific field [39].

\section{MECHANISM OF ACTION OF VORTIOXETINE}

Vortioxetine has 5-HT3, 5-HT7 and 5-HT1D receptor antagonists, 5-HT1B receptor partial agonist and a 5-HT1A receptor agonist and serotonin transporter (SERT) inhibitor property as has been demonstrated by an in vitro assay [40]. The ex vivo autoradiography assay revealed an affinity for 5HT3 receptors and SERT appeared to be especially high. Vortioxetine increases the extracellular concentration of serotonin (5-HT) in brain areas involved in pathophysiology of depression, such as the medial prefrontal cortex and the hippocampus. This action appears to be even stronger than the one caused by the selective reuptake inhibitors of serotonin (SSRI) $[41,42]$. The blockade of 5-HT3 receptors by vortioxetine may be involved in the powerful elevations of ex- 
tracellular 5-HT and it is one of the factors distinguishing the action of this drug by SSRIs [43, 44]. In rat brain a similar elevation of the extracellular neurotransmitter was found with respect to noradrenaline (NA), dopamine (DA), acetylcholine (Ach), and histamine (HA) after vortioxetine treatment $[41,45]$.

Studies on drugs active on glutamatergic neurotransmission have shown new opportunities for the treatment of depressive disorders: Ketamine shows an antidepressant effect mediated through glutamate pathways [45]. It is possible to enhance glutamate transmission indirectly through the 5-HT system through the 5-HT1A, 5-HT1B, 5-HT3, and 5-HT7 receptors, in combination with 5-HT transporter inhibition. Vortioxetine can provide an example of serotonergic modulation of glutamate transmission and it may be the basis of its efficacy on depression as well on the associated cognitive dysfunction [45].

Studies on the effect of vortioxetine on synaptic transmission, long-term potentiation (LTP), and theta oscillations in the rat hippocampus and frontal cortex have indicated that vortioxetine can increase pyramidal cell output, which leads to enhanced synaptic plasticity in the hippocampus. Given the central role of the hippocampus in cognition, these findings may provide a cellular correlate to the observed preclinical and clinical cognition-enhancing effects of vortioxetine [46] (Dale et al. 2014).

Vortioxetine has a half-life of 57 hours, and it reaches stable concentrations in the plasma in $<2$ weeks. It binds to plasma proteins at $96 \%$ [47]. Vortioxetina is metabolized by the isoenzymes P-450 of liver CYP2D6, CYP3A4/5, CYP2C9, CYP2C19, CYP2A6, CYP2C8, and CYP2B6, but as it has linear kinetics, it does not inhibit or activate them [48] Its main metabolite is inactive [47].

\section{EFFECT ON NEUROGENESIS AND CONSE- QUENCES FOR DEPRESSION AND COGNITIVE FUNCTIONS}

A deficit of neurogenesis impairing the processes of oxidation in the brain may have a role in the pathogenesis of Depressive Disorders [49-53].

In the hippocampus the effect of increasing extracellular levels of some neurotransmitters such as glutamate through metabotropic receptors can lead the up-regulation of Arc mRNA levels to stimulating synaptic plasticity with structural remodeling and functional changes [54, 55]. On studying other drugs, these effects were found associated with improvement in cognition and depressive-like behavior [56] Vortioxetine via glutamatergic system stimulation can produce these effects in conjunction with other synergistic effects such as the low-dosage blockade of 5-HT7 receptors that improves cognition and increases mood [57, 58].

In fact, pre-clinical studies in mice found that vortioxetine significantly increases cell proliferation, cell survival and maturation of immature granule cells in the subgranular zone of the dentate gyrus of the hippocampus after 21 days of treatment. Vortioxetine accelerates the maturation of immature neurons as it increases the dendritic length and the quantity of dendrite intersections. These effects were observed at low levels of 5-HT transporter occupancy, thus with a mechanism of action alternative to 5-HT reuptake inhibition [59].

\section{EFFICACY OF VORTOXETINE IN MAJOR DE- PRESSIVE DISORDERS}

Twelve short-term (6-12 weeks) randomized clinical trials were found in the meta-analysis by [60] and the review by [47]. Ten cited papers are exactly the same ones cited in the previous two papers [61-70].

Each study cited two different papers but each of them seem apparently to come from the same trial of the corresponding paper cited in the other study [71-74].

Six RCTs compared Vortioxetine with an active control other than placebo (Venlafaxine extended-release, Duloxetine); one was with Agomelatine without a placebo arm and five compared Vortioxetine with placebo. Even though the diagnosis of MDD was carried out according to DSM-IV-TR criteria, the studies showed different inclusion criteria: severity of MDD measured with the Montgomery-Åsberg Depression Rating Scale (MADRS) was 22, 26 or 30. Exclusion criteria included treatment-resistant depression or comorbid with psychiatric or physical conditions. The doses of active drug varied $1,2.5,5,10,15$ and $20 \mathrm{mg} / \mathrm{d}$, once daily [60]. The primary outcome measures were the mean change from baseline in total scores on the Hamilton Rating Scale for Depression (HAM-D) or in the MADRS, as defined in each study. All the trials made the intention-to-treat analysis with the last observation carried forward (LOCF) but including all patients who fulfilled at least one assessment after randomization.

Eight studies comparing vortioxetine to placebo showed positive results for vortioxetine, and four studies showed no significant differences against placebo [47].

As regards primary end-point overall efficacy, the eleven studies show vortioxetine efficacy against placebo with an SMD of $-0.217(95 \%$ CI -0.313 to -0.122$)$ in a pooled sample of 4947 patients (vortioxetine, $n=3276$ v. placebo, $n=$ 1671), [60].

Comparing the secondary end-point, Vortioxetine shows an OR of $1.652(95 \%$ CI 1.321-2.067) for response and an OR of $1.399(95 \%$ CI $1.104-1.773)$ for remission against placebo [60].

The majority of positive studies achieved positive results in the arms with 5-20 mg/day only in two positive studies: vortioxetine was superior to placebo only in the dose arms of $20 \mathrm{mg} /$ day (Alvarez et al. 2014).

Improvement with vortioxetine appeared after approximately 2 weeks of treatment, with the maximum response at the fourth week [47]. Only the trial by McIntyre [71] showed improvement at the first week but only in the arm with 20 $\mathrm{mg} /$ day.

The efficacy of Vortioxetine versus other antidepressants was provided by a sample of 2843 (vortioxetine, $n=1847$ ) patients drawn from the seven cited studies. It showed for the primary analysis a SMD of 0.081 (95\% CI -0.062 to 0.223 ) and revealed no difference between the treatment groups. 
The percentage of patients in each trial who completed the full study ranged from $74 \%$ to $90 \%$.

As regards the issue addressed in this paper, the trial by Katona et al. [69] is of specific interest as it concerns patients aged 65 and over, the age group with the highest risk of cerebrovascular diseases. It was an 8-week three arm randomized clinical trial comparing placebo, duloxetine $60 \mathrm{mg}$ and vortioxetine $5 \mathrm{mg}$. Both active comparisons were found superior to placebo at week 8 as concerns the primary efficacy outcome: with a decrease in the HAMD score (last observation carried forward). The interesting findings concerning cognitive performance and adverse effect will be discussed in the dedicated paragraphs.

Another interesting trial is the 12-week one by Häggström et al. [72] who recruited non-responding or inadequately responding patients to SSRI or SNRI monotherapy. The patients were randomized to receive agomelatine (25-50 $\mathrm{mg}$ /day) or vortioxetine (10-20 mg/day). At the end of the trial patients had improved significantly in both groups (16.5 points MADRS in vortioxetine; 14.4 points in agomelatine on the average). However, both in therapeutic response and remissions vortioxetine was found better than agomelatine.

One long-term efficacy randomized double-blind controlled multicenter clinical trial was designed to assess prevention of relapses with duloxetine [75]. The 639 patients recruited were treated with open-label flexible doses of vortioxetine for 12 -weeks $(5-10 \mathrm{mg} /$ day $)$; the dose was then fixed. Remitted patients were randomized to placebo or vortioxetine and then followed for at least 24 weeks. The mean relapse rate was higher in the placebo group (26\% against $13 \%, \mathrm{P}=0.0035)$ [75].

\section{VORTIOXETINE TOLERABILITY}

Most AEs found in the aforementioned trial were nausea, vomiting, constipation and headaches. The AEs caused by vortioxetine were higher than those by placebo only at the highest $(20 \mathrm{mg} /$ day) dose, ranging from $15.8 \%$ more than placebo [75] to $10.8 \%$ less than placebo [63].

In the trial on elderly patients, the only adverse event in which the incidence was found higher with vortioxetine than placebo was nausea $(21.8 \%$ vs $8.3 \%)$. Duloxetine had a higher incidence than placebo of nausea, constipation, hyperhidrosis and somnolence.

Sexual dysfunctions reported by vortioxetine users were similar to those of people assuming placebo [47].

The trend of AE-related withdrawals, considering all the aforementioned trials at $10 \mathrm{mg}$ or more, was greater in the vortioxetine arms versus placebo and lower than the active comparator [47].

The AE-related withdrawal rates in the trial on older people by Katona et al. [69] were $2.8 \%$ for placebo, $5.8 \%$ for vortioxetine and $9.9 \%$ for duloxetine [69].

A crucial point concerning the potential use of the drug on cerebrovascular disease is that vortioxetine was found similar to placebo in its impact on vital signs such as arterial blood pressure and heart rate, as well as on cardiac parameters - including the QT segments at ECG.

\section{COGNITIVE FUNCTIONS AND USE OF VORTI- OXETINE}

Vortioxetine has been shown to improve cognitive performance in several preclinical rat models [46] and it is supposed that vortioxetine's effects on recognition and spatial working memory assessed in the Y-maze spontaneous alternation test performance may involve 5-HT1A receptor agonism, whereas the effects on recognition and spatial working memory assessed in the object recognition test performance may involve 5-HT3 receptor antagonism and 5-HT1A receptor agonism [76].

Taking into account these pre-clinical findings, the study by Katona et al. (2012) on the treatment of depression in old age is of great relevance. This survey offers data on the assessment of cognitive function with baseline end of the study comparison for verbal learning, memory, and processing speed measured by means of the Rey Auditory Verbal Learning Test (RAVLT) and the digit symbol substitution test (DSST). The inclusion criteria admitted patients with a mini-mental state (MMSE) score of at least 24 points, thus eliminating cases with severe neurodegenerative disease or severe cerebrovascular disease, but not cases with middle cerebrovascular disease. Patients on vortioxetine showed significantly greater improvement versus placebo and versus the other active comparators in both DSST and RAVLT scores.

A trial carried out by Theunissen et al. [77] measured the effect of vortioxetine at a dose of $20 / \mathrm{mg}$ per day, placebo and mirtazapine on driving and some related cognitive functions in healthy subjects. Vortioxetine assumption was not associated with impairment of driving and in cognitive function throughout the trial (16 days); in contrast, mirtazapine was not at the beginning owing to sedation.

\section{CONCLUSION}

The mechanism of action, the efficacy on depression and safety profile and early data on cognitive impairment make Vortioxetine a strong candidate for use in depression associated with cerebrovascular disease. This information must be supported by future randomized controlled trials

\section{CONFLICT OF INTEREST}

Prof Mauro Giovanni Carta has received grants from the European Commission, European Social Fund, AIFA (Agenzia Italiana del Farmaco), Fondazione Banco di Sardegna and the Sardinia Region. Prof Carta is advisor for the Economic and Social Committee of the European Union. Dr Andrea Norcini-Pala didn't receive founds or grants by drug companies. Dr Maria Francesca Moro received grants from Fondazione Banco di Sardegna.

\section{ACKNOWLEDGEMENTS}

Declared none.

\section{REFERENCES}

[1] Celermajer DS, Chow CK, Marijon E, Anstey NM, Woo KS. Cardiovascular disease in the developing world prevalences, patterns, and the potential of early disease detection. J Am Coll Cardiol 2012; 60(14): 1207-16. 
[2] Brott TG, Halperin JL, Abbara S, et al. ASA/ACCF/AHA/AANN/ AANS/ACR/ASNR/CNS/SAIP/SCAI/SIR/ SNIS/SVM/SVS guideline on the management of patients with extracranial carotid and vertebral artery disease. Circulation 2011; 124(4): e54-130. [Epub 2011/02/02].

[3] Lloyd-Jones D, Adams RJ, Brown TM, et al. Executive summary: heart disease and stroke statistics--2010 update: a report from the American Heart Association. Circulation 2010; 121(7): 948-54.

[4] Rocque BG, Jackson D, Varghese $\mathrm{T}$, et al. Impaired cognitive function in patients with atherosclerotic carotid stenosis and correlation with ultrasound strain measurements. J Neurol Sci 2012; 322(1-2): 20-4. doi: 10.1016/j.jns.2012.05.020. [Epub 2012 Jun 1].

[5] de Weerd M, Greving JP, Hedblad B, et al. Prediction of asymptomatic carotid artery stenosis in the general population: identification of high-risk groups. Stroke 2014; 45(8): 2366-71.

[6] Vieweg WV, Julius DA, Fernandez A, et al. Treatment of depression in patients with coronary heart disease. Am J Med 2006; 119(7): 567-73

[7] Moussavi S, Chatterji S, Verdes E, Tandon A, Patel V, Ustun B. Depression, chronic diseases [no virgola] and decrements in health: results from the World Health Surveys. Lancet 2007; 370: 851-8.

[8] Egede LE. Major depression in individuals with chronic medical disorders: prevalence, correlates and association with health resource utilization, lost productivity and functional disability. Gen Hosp Psychiatry 2007; 29: 409-16.

[9] Ali S, Stone MA, Peters JL, Davies MJ, Khunti K. The prevalence of co-morbid depression in adults with Type 2 diabetes: a systematic review and meta-analysis. Diabet Med 2006; 23: 1165-73.

[10] Hadidi N, Treat-Jacobson DJ, Lindquist R. Poststroke depression and functional outcome: a critical review of literature. Hear Lung 2009; 38: 151-62.

[11] Carta MG, Lecca ME, Saba L, et al. Patients with Carotid Atherosclerosis who underwent or did not undergo carotid endarterectomy (CEA): outcome on mood, cognition and quality of life. BMC Psychiatry Submitted.

[12] Whooley MA, De JP, Vittinghoff E, et al. Depressive symptoms, health behaviors, and risk of cardiovascular events in patients with coronary heart disease. JAMA 2008; 300: 2379-88.

[13] Alexopoulos GS, Kiosses DN, Klimstra S, et al. Clinical presentation of the "depression-executive dysfunction syndrome" of late life. Am J Geriatr Psychiatry 2002; 10: 98-106.

[14] Sneed JR, Culang-Reinlieb ME. The vascular depression hypothesis: An update. Am J Geriatr Psychiatry 2011; 19(2): 99-103.

[15] Alexopoulos GS, Kiosses DN, Choi SJ, et al. Frontal white matter microstructure and treatment response of late-life depression: a preliminary study. Am J Psychiatry 2002; 159: 1929-32.

[16] Krishnan KR, Taylor WD, McQuoid DR, et al. Clinical characteristics of magnetic resonance imaging-defined subcortical ischemic depression. Biological Psychiatry 2004; 55:390-7.

[17] Krishnan V, Nestler EJ. Linking molecules to mood: new insight into the biology of depression. Am J Psychiatry 2010; 167: 130520 .

[18] Sneed JR, Culang ME, Keilp JG, et al. Antidepressant medication and executive dysfunction: a deleterious interaction in late-life depression. Am J Geriatr Psychiatry 2010; 18: 128-35.

[19] Kim BS, Lee DH, Lee DW, et al. The role of vascular risk factors in the development of DED syndrome among an elderly community sample. Am J Geriatr Psychiatry 2011; 19(2): 104-14. doi: 10.1097/JGP.0b013e31820119b6.

[20] Arauz A, Rodríguez-Agudelo Y, Sosa AL, et al. Vascular cognitive disorders and depression after first-ever stroke: the fogarty-Mexico stroke cohort. Cerebrovasc Dis 2014; 38(4): 284-9. [Epub ahead of print]

[21] Taylor WD, MacFall JR, Payne ME, et al. Orbitofrontal cortex volume in late life depression: influence of hyperintense lesions and genetic polymorphisms. Psychol Med 2007; 37: 1763-73.

[22] Artero S, Tiemeier H, Prins ND, et al. Neuroanatomical localization and clinical correlates of white matter lesions in the elderly. $\mathrm{J}$ Neurol Neurosurg 2004; 75: 1304-8.

[23] Rajkowska G, Miguel-Hidalgo JJ, Dubey P, et al. Prominent reduction in pyramidal neurons density in the orbitofrontal cortex of elderly depressed patients. Biological Psychiatry 2005; 58: 297-306.

[24] Khundakar A, Morris C, Oakley A, Thomas AJ. Morphometric analysis of neuronal and glial cell pathology in the caudate nucleus in late-life depression. Am J Geriatr Psychiatry 2011; 19(2): 13241 .
[25] Nabavi SF, Dean OM, Turner A, Sureda A, Daglia M, Nabavi SM. Oxidative stress and post-stroke depression: possible therapeutic role of polyphenols? Curr Med Chem 2015; 22(3): 343-51.

[26] Li F, Fei D, Sun L, et al. Neuroprotective effect of bone marrow stromal cell combination with atorvastatin in rat model of spinal cord injury. Int J Clin Exp Med 2014; 7(12): 4967-74

[27] Henry G, Williamson D, Tampi RR. Efficacy and tolerability of antidepressants in the treatment of behavioral and psychological symptoms of dementia, a literature review of evidence. Am J Alzheimers Dis Other Demen 2011; 26(3): 169-83. doi: $10.1177 /$ 1533317511402051

[28] Mazza M, Lotrionte M, Biondi-Zoccai G, Abbate A, Sheiban I, Romagnoli E. Selective serotonin reuptake inhibitors provide significant lower re-hospitalization rates in patients recovering from acute coronary syndromes: evidence from a meta-analysis. J Psychopharmacol 2010; 24: 1785-92.

[29] Pizzi C, Rutjes AW, Costa GM, Fontana F, Mezzetti A, Manzoli L. Meta-analysis of selective serotonin reuptake inhibitors in patients with depression and coronary heart disease. Am J Cardiol 2011; 107: $972-9$

[30] Liu X, Zhang J, Sun D, Fan Y, Zhou H, Fu B. Effects of fluoxetine on brain-derived neurotrophic factor serum concentration and cognition in patients with vascular dementia. Clin Interv Aging 2014; 9: 411-8. doi: 10.2147/CIA.S58830.

[31] Kurumatani T, Takeda M. Vascular depression. Nihon Rinsho 2001; 59(8): 1574-7.

[32] de Abajo FJ, Montero D, Rodriguez LA, Madurga M. Antidepressants and risk of upper gastrointestinal bleeding. Basic Clin Pharmacol Toxicol 2006; 98: 304-10.

[33] Kimura A, Iwamoto T. Acute massive gastrointestinal bleeding in the elderly. Nihon Ronen Igakkai Zasshi 2009; 46(3): 250-8.

[34] FDA Drug Safety Communication: Abnormal heart rhythms associated with high doses of Celexa (citalopram hydrobromide) 2011. Available at: http://www.fda.gov/Drugs/DrugSafety/ucm 269086.htm.

[35] Rieckmann N, Kronish IM, Shapiro PA, Whang W, Davidson KW Serotonin reuptake inhibitor use, depression, and long-term outcomes after an acute coronary syndrome: a prospective cohort study. JAMA Intern Med 2013; 173(12): 1150-1. doi: 10.1001/ jamainternmed.2013.910.

[36] Oudman E. Is electroconvulsive therapy (ECT) effective and safe for treatment of depression in dementia? A short review. J ECT 2012; 28(1): 34-8.

[37] Alexopoulos GS, Raue P, Arean P. Problem-solving therapy versus supportive therapy in geriatric major depression with executive dysfunction. Am J Geriatr Psychiat 2003; 11: 46-52.

[38] Kiosses DN, Arean PA, Teri L, Alexopoulos GS. Home-delivered problem adaptation therapy (PATH) for depressed, cognitively impaired, disabled elders: a preliminary study. Am J Geriatr Psychiatry 2010; 18(11): 988-98. doi: 10.1097/JGP.0b013e3181d6947d

[39] Koenig AM, Butters MA. Cognition in late life depression: treatment considerations. Curr Treat Options Psychiatry 2014; 1(1): 114

[40] Westrich L, Pehrson A, Zhong $\mathrm{H}$, et al. In vitro and in vivo effects of the multimodal antidepressant vortioxetine (Lu AA21004) at human and rat targets. Int J Psychiatr Clin Pract 2012; 16(Suppl 1): 47.

[41] Mørk A, Pehrson A, Brennum LT, et al. Pharmacological effects of Lu AA21004: a novel multimodal compound for the treatment of major depressive disorder. J Pharmacol Exp Ther 2012; 340(3): 666-75.

[42] Pehrson AL, Cremers T, Bétry C, et al. Lu AA21004, a novel multimodal antidepressant, produces regionally selective increases of multiple neurotransmitters - a rat microdialysis and electrophysiology study. Eur Neuropsychopharmacol 2013; 23(2): 133-45.

[43] Artigas F. Serotonin receptors involved in antidepressant effects Pharmacol Ther 2013; 137(1):119-31.

[44] Artigas F, Romero L, de Montigny C, Blier P. Acceleration of the effect of selected antidepressant drugs in major depression by 5 HT1A antagonists. Trends Neurosci 1996; 19(9): 378-83.

[45] Pehrson AL, Sanchez C. Serotonergic modulation of glutamate neurotransmission as a strategy for treating depression and cognitive dysfunction. CNS Spectr 2014; 19(2): 121-33. doi: 10.1017/ S1092852913000540. [Epub 2013 Aug 1].

[46] Dale E, Zhang H, Leiser SC, et al. Vortioxetine disinhibits pyramidal cell function and enhances synaptic plasticity in the rat hippo- 
campus. J Psychopharmacol 2014; 28(10): 891-902. doi: 10.1177/ 0269881114543719.

[47] Alvarez E, Perez V, Artigas F. Pharmacology and clinical potential of vortioxetine in the treatment of major depressive disorder. Neuropsychiatr Dis Treat 2014; 10: 1297-307. doi: 10.2147/ NDT.S41387.

[48] Hvenegaard MG, Bang-Andersen B, Pedersen H, Jørgensen M, Püschl A, Dalgaard L. Identification of the cytochrome P450 and other enzymes involved in the in vitro oxidative metabolism of a novel antidepressant, Lu AA21004. Drug Metab Dispos 2012; 40(7): 1357-65.

[49] Hussaini SM, Choi CI, Cho CH, Kim HJ, Jun H, Jang MH. Wnt signaling in neuropsychiatric disorders: ties with adult hippocampal neurogenesis and behavior. Neurosci Biobehav Rev 2014; 47: 36983. doi: 10.1016/j.neubiorev.2014.09.005. [Epub 2014 Sep 28].

[50] Carta MG, Moro MF, Lorefice L, et al. The risk of Bipolar Disorders in Multiple Sclerosis. J Affect Disord 2014; 155: 255-60. doi: 10.1016/j.jad.2013.11.008.

[51] Carta MG, Bhat KM, Preti A. GABAergic neuroactive steroids: a new frontier in bipolar disorders? Behav Brain Funct 2012; 8(1): 61.

[52] Carta MG, Sorbello O, Moro MF, et al. Bipolar disorders and Wilson's disease. BMC Psychiatry 2012; 12(1): 52.

[53] Hardoy MC, Serra M, Carta MG, Contu P, Pisu MG, Biggio G. Increased neuroactive steroid concentrations in women with bipolar disorder or major depressive disorder. J Clin Psychopharmacol 2006; 26(4): 379-84.

[54] Bramham CR, Worley PF, Moore MJ, Guzowski JF. The immediate early gene arc/arg3.1: regulation, mechanisms, and function. J Neurosci 2008; 28: 11760-7.

[55] Guzowski JF, Lyford GL, Stevenson GD, et al. Inhibition of activity-dependent arc protein expression in the rat hippocampus impairs the maintenance of long-term potentiation and the consolidation of long-term memory. J Neurosci 2000; 20: 3993-4001.

[56] Cates LN, Roberts AJ, Huitron-Resendiz S, Hedlund PB. Effects of lurasidone in behavior models of depression. Role of the 5-HT receptor subtype. Neuropharmacology 2013; 70C: 211-7.

[57] Wesolowska A, Tatarczynska E, Nikiforuk A, Chojnacka-Wojcik E. Enhancement of the anti-immobility action of antidepressants by a selective 5-HT7 receptor antagonist in the forced swimming test in mice. Eur J Pharmacol 2007; 555: 43-7.

[58] Roberts AJ, Hedlund PB. The 5-HT(7) receptor in learning and memory. Hippocampus 2012; 22: 762-71.

[59] Guilloux JP, Mendez-David I, Pehrson A, et al. Antidepressant and anxiolytic potential of the multimodal antidepressant vortioxetine (Lu AA21004) assessed by behavioural and neurogenesis outcomes in mice. Neuropharmacology 2013; 73: 147-59. doi: 10.1016/ j.neuropharm.2013.05.014. [Epub 2013 May 28].

[60] Pae CU, Wang SM, Han C, et al. Vortioxetine: a meta-analysis of 12 short-term, randomized, placebo-controlled clinical trials for the treatment of major depressive disorder. J Psychiatry Neurosci. 2014; 39(6): 140120. doi: 10.1503/jpn.140120. [Epub ahead of print]

[61] Jain R, Mahableshwarkar AR, Jacobsen PL, Chen Y, Thase ME. A randomized, double-blind, placebo-controlled 6-wk trial of the efficacy and tolerability of $5 \mathrm{mg}$ vortioxetine in adults with major depressive disorder. Int J Neuropsychopharmacol 2013; 16(2): 31321.

[62] Baldwin DS, Loft H, Dragheim M. A randomised, double-blind, placebo controlled, duloxetine-referenced, fixed-dose study of three dosages of Lu AA21004 in acute treatment of major depressive disorder (MDD). Eur Neuropsychopharmacol 2012; 22(7): 482-91.

[63] Mahableshwarkar AR, Jacobsen PL, Serenko M, Chen Y, Trivedi MH. A duloxetine-referenced, fixed dose study comparing efficacy and safety of 2 vortioxetine doses in the acute treatment of adult MDD patients; Poster presented at: American Psychiatry Association Annual Meeting; San Francisco, CA, May 18-22, 2013a.

[64] Mahableshwarkar AR, Jacobsen PL, Chen Y. A randomized, double-blind trial of $2.5 \mathrm{mg}$ and $5 \mathrm{mg}$ vortioxetine ( $\mathrm{Lu}$ AA21004) ver- sus placebo for 8 weeks in adults with major depressive disorder. Curr Med Res Opin 2013b; 29(3): 217-26.

[65] Mahableshwarkar AR, Jacobsen PL, Serenko M, Chen Y, Trivedi $\mathrm{MH}$. A randomized, double blind, parallel, placebo-controlled, fixed-dose study comparing the efficacy and safety of 2 doses of vortioxetine (LU AA21004) in acute treatment of adults with major depressive disorder; Poster presented at: American Psychiatry Association Annual Meeting; San Francisco, CA, May 18-22, 2013c.

[66] Jacobsen PL, Mahableshwarkar AR, Serenko M, Chan S, Trivedi $\mathrm{MH}$. A randomized, double-blind, placebo-controlled study of the efficacy and safety of vortioxetine $10 \mathrm{mg}$ and $20 \mathrm{mg}$ in adults with Major Depressive Disorder; Poster presented at: American Psychiatry Association Annual Meeting; San Francisco, CA, May 18-22, 2013a.

[67] Alvarez E, Perez V, Dragheim M, Loft H, Artigas F. A doubleblind, randomized, placebo-controlled, active reference study of $\mathrm{Lu}$ AA21004 in patients with major depressive disorder. Int J Neuropsychopharmacol 2012; 15(5): 589-600.

[68] Henigsberg N, Mahableshwarkar AR, Jacobsen P, Chen Y, Thase ME. A randomized, double-blind, placebo-controlled 8-week trial of the efficacy and tolerability of multiple doses of Lu AA21004 in adults with major depressive disorder. J Clin Psychiatry 2012; 73(7): 953-9.

[69] Katona C, Hansen T, Olsen CK. A randomized, double-blind, placebo-controlled, duloxetine-referenced, fixed-dose study comparing the efficacy and safety of Lu AA21004 in elderly patients with major depressive disorder. Int Clin Psychopharmacol 2012; 27(4): 215-23.

[70] Boulenger JP, Loft H, Olsen CK. Efficacy and safety of vortioxetine (Lu AA21004), 15 and $20 \mathrm{mg}$ /day: a randomized, double-blind, placebo-controlled, duloxetine-referenced study in the acute treatment of adult patients with major depressive disorder. Int Clin Psychopharmacol 2014; 29(3): 138-49.

[71] McIntyre RS, Lophaven S, Olsen CK. Randomized, double-blind, placebo-controlled study of the efficacy of vortioxetine on cognitive function in adult patients with major depressive disorder (MDD); Poster presented at: $52^{\text {nd }}$ Annual Meeting of the American College of Neuropsychopharmacology (ACNP); Hollywood, FL, December 8-12, 2013.

[72] Häggström L, Nielsen RZ, Poulsen L, Danchenko N. A randomised, double blind, active controlled study of vortioxetine (10-20 $\mathrm{mg}$ /day) versus agomelatine $25-50 \mathrm{mg}$ /day) in adults with Major Depressive Disorder with inadequate response to antidepressant treatment; Poster presented at: $26^{\text {th }}$ Congress of the European College of Neuropsychopharmacology (ECNP); Barcelona, Spain, October 5-9, 2013.

[73] NCT01255787. Efficacy and safety study of vortioxetine (Lu AA21004) for treatment of major depressive disorder. Available: http://clinicaltrials.gov/show/NCT01255787 [accessed 2014 Apr. $1]$.

[74] Dragheim M, Nielsen RZ. A randomized, double-blind, study of vortioxetine versus agomelatine in adults with major depressive disorder (MDD) switched after inadequate response to SSRI or SNRI treatment (NCT01488071) [poster]. NCDEU 53 ${ }^{\text {rd }}$ Annual Meeting; Hollywood, FL, 2013 May 28-31.

[75] Boulenger JP, Loft H, Florea I. A randomized clinical study of Lu AA21004 in the prevention of relapse in patients with major depressive disorder. J Psychopharmacol 2012; 26(11): 1408-16.

[76] du Jardin KG, Jensen JB, Sanchez C, Pehrson AL. Vortioxetine dose-dependently reverses 5-HT depletion-induced deficits in spatial working and object recognition memory: a potential role for 5HT1A receptor agonism and 5-HT3 receptor antagonism. Eur Neuropsychopharmacol 2014; 24(1): 160-71.

[77] Theunissen EL, Street D, Hojer AM, et al. A randomized trial on the acute and steady-state effects of a new antidepressant, vortioxetine ( $\mathrm{Lu}$ AA21004), on actual driving and cognition. Clin Pharmacol Ther 2013; 93(6): 493-501.

(C) Carta et al.; Licensee Bentham Open.

This is an open access article licensed under the terms of the Creative Commons Attribution Non-Commercial License (http://creativecommons.org/licenses/by-nc/3.0/) which permits unrestricted, non-commercial use, distribution and reproduction in any medium, provided the work is properly cited. 